\title{
A reestruturação do currículo do Ensino Médio e a interdisciplinaridade'.
}

\author{
Rafael da Silva Cortes ${ }^{2}$
}

\begin{abstract}
Resumo
Este artigo procura abordar o tema da organização interdisciplinar nos currículos nacionais para o Ensino Médio. Para tanto, recordamos a temática da interdisciplinaridade nos documentos oficiais, desde a Lei de Diretrizes e Bases da Educação Nacional (Lei 9394/96) até as Diretrizes Curriculares Nacionais para a Educação Básica de 2013 e constatamos que existem poucas propostas metodológicas de organização colaborativa dos currículos. Sendo assim, apresentamos a "transversalidade pedestre" como proposta de organização interdisciplinar do currículo, utilizadas em aulas de filosofia no Colégio de Aplicação da Universidade Federal do Rio Grande do Sul. Por fim, refletimos sobre as vantagens da metodologia apresentada dentro do contexto de crescente exigência de currículos integrados na última etapa da educação básica.
\end{abstract}

Palavras-chave: currículo; ensino médio; interdisciplinaridade.

\section{The reestructuring of the high school's curriculum and interdisciplinarity}

\begin{abstract}
This paper aims to address the issue of interdisciplinary organization in national curriculum for high school. Therefore, we remember the issue of interdisciplinarity in official documents, from the Lei de diretrizes e bases da educação nacional (Law 9394/96) to the Diretrizes curriculares nacionais para a educação básica of 2013, and we noticed that there are few methodological proposals to organizing collaborative curriculum. Thus, we present the "transversalidade pedestre" as suggestion to organizing an interdisciplinary curriculum, used in classes of philosophy at Colégio de Aplicação. Finally, we reflect on advantages that methodology in the context of growing demand for integrated curriculum in the last step of basic education.
\end{abstract}

Keywords: curriculum; high school; interdisciplinarity.

\footnotetext{
1 A versão resumida desse ensaio foi apresentada no IX Seminário Filosofia na Escola e V Seminário PIBID - Filosofia, realizados nos dias 4 e 5 de Dezembro de 2014, no Campus da Universidade Federal de Santa Maria (UFSM) na cidade de Santa Maria/RS.

2 Professor de Filosofia do Colégio de Aplicação da Universidade Federal do Rio Grande do Sul (CAp/UFRGS). Doutorando em Filosofia no programa de pós-graduação em Filosofia da UFSM. E-mail: raf.cortes@yahoo.com.br
} 


\section{Introdução}

Vivemos um momento de fundamentais mudanças na estrutura curricular da educação básica (pública) brasileira. Um modelo curricular no qual as disciplinas pouco dialogam entre si e que também por isso, fazem pouco sentido para os adolescentes está sendo suplantado e abrindo caminho para uma organização mais colaborativa. Entendo que tal mudança de perspectiva sobre o currículo do ensino médio tem dois fatores motivadores principais. Primeiro: o aumento das expectativas da comunidade escolar brasileira em relação à capacidade formativa do ensino básico como um todo3; segundo: maior dinâmica no consumo de informações sobre o mundo pelos estudantes, especialmente os de nível médio4. Nesse sentido, creio ser intelectualmente honesto reconhecer que nos últimos anos diversas medidas governamentais têm sido desenvolvidas para efetivar mudanças curriculares, focando-se sobremaneira na interdisciplinaridade.

Na tentativa de entender melhor as mais recentes mudanças no ensino médio, organizei este texto do seguinte modo: na primeira parte aponto indícios legais e normativos através dos quais creio ser possível sustentar a afirmação de que estamos vivendo uma importante reorganização do ensino médio; na segunda parte exponho a fundamentação metodológica das ações interdisciplinares que desenvolvo no Colégio de Aplicação (CAp/UFRGS); por fim, faço um breve relato de três dessas atividades desenvolvidas no CAp na disciplina de Filosofia.

\section{O currículo do EM nos documentos federais e a interdisciplinaridade}

Desde a LDB (9394/96) podemos identificar prescrições sobre a reorganização do currículo do ensino médio. Na referida lei encontramos, por exemplo, o artigo 26 que reza o seguinte: "Os currículos da educação infantil, do ensino fundamental e do ensino médio devem ter uma base nacional comum, a ser

\footnotetext{
3 Nesse aspecto estão incluídas as finalidades da educação básica determinadas por leis e regulamentações.

${ }^{4}$ Devo admitir que os dois aspectos aqui apontados são constatações empíricas baseadas na minha experiência como professor, e não possuem comprovação empírica. Contudo, ao lermos os documentos federais sobre educação básica notamos que seus autores também identificam motivos muito similares aos aqui apontados para justificar as mudanças no perfil do currículo do ensino médio nacional.
} 
complementada, em cada sistema de ensino e estabelecimento escolar, por uma base diversificada, exigida pelas características regionais e locais da sociedade, da cultura, da economia e da clientela5". Muito embora essa passagem e nos demais artigos da LDB não existam referências explicitas à interdisciplinaridade, observamos já em 1996 a sugestão para pensarmos sobre o modelo curricular vigente.

Já nos Parâmetros Curriculares Nacionais (PCN) de 2000 encontramos a defesa mais clara de uma mudança na organização dos currículos do ensino médio, cujo fim, segundo os autores, deveria ser o desenvolvimento de competências e habilidades dos estudantes. Segundo a perspectiva focada nas competências e habilidades os conteúdos das disciplinas não deveriam mais ser assumidos pelos professores como fins do ensino, mas sim como meios que facilitariam o alcance de fins maiores: o desenvolvimento de competências e habilidades dos estudantes, tais como leitura, escrita e visão crítica do mundo. É nesse contexto que a interdisciplinaridade passou a ganhar mais atenção e a ser considerada uma metodologia de organização curricular que viabilizaria o alcance daqueles fins, conforme podemos ler na seguinte passagem dos PCN (2000, p. 4):

- MEC chegou ao um novo perfil de currículo, apoiado em competências básicas para a inserção de nossos jovens na vida adulta. Tínhamos um ensino descontextualizado, compartimentalizado e baseado no acúmulo de informações. Ao contrário disso, buscamos dar significado ao conhecimento escolar, mediante a contextualização; evitar a compartimentalização, mediante a interdisciplinaridade [...].

Seguindo o caminho dos PCN, nos PCN+ de 2002 a ênfase na interdisciplinaridade é ainda maior, como evidencia o fragmento a seguinte: "Antes se desejava transmitir conhecimentos disciplinares padronizados, na forma de informações e procedimentos estanques; agora se deseja promover competências gerais, que articulem conhecimentos disciplinares" (2002, p. 12).

\footnotetext{
5 Grifos meus. Redação do Art. 26 aprovada pela Lei 12.796 de 2013. A redação anterior era muito similar a atual, como podemos perceber no que segue: "Os currículos do ensino fundamental e médio devem ter uma base nacional comum, a ser complementada, em cada sistema de ensino e estabelecimento escolar, por uma parte diversificada, exigida pelas características regionais e locais da sociedade, da cultura, da economia e da clientela".
} 
Passados mais de dez anos do PCN+, em 2013 o MEC publica as novas Diretrizes nacionais para a educação básica que consiste no documento mais recente que visa prescrever orientações para a educação básica do país e que mais claramente destaca a interdisciplinaridade como metodologia de organização curricular. Lê-se nas Diretrizes (2013, p. 186):

\begin{abstract}
A interdisciplinaridade é, portanto, uma abordagem que facilita o exercício da transversalidade, constituindo-se em caminhos facilitadores da integração do processo formativo dos estudantes, pois ainda permite a sua participação na escolha dos temas prioritários. A interdisciplinaridade e a transversalidade complementam-se, ambas rejeitando a concepção de conhecimento que toma a realidade como algo estável, pronto e acabado [...]
\end{abstract}

Diante do brevemente exposto acerca da interdisciplinaridade nos documentos nacionais, pode-se notar o gradativo aumento das exigências governamentais por uma reestruturação dos currículos da última etapa da educação básica visando, dessa maneira, maior interação entre as diferentes áreas de conhecimento. Além disso, não podemos esquecer o mais recente edital do livro didático (2015 - 2018) que exigiu das editoras e dos autores livros cujos conteúdos fossem trabalhados interdisciplinarmente. Ora, sem analisar aqui alguns aspectos questionáveis sobre as concepções de interdisciplinaridade apregoadas pelos documentos supramencionados, nota-se ao menos certa disposição das instancias administrativas e reguladoras da educação básica do país em propor a reflexão sobre a reorganização curricular do ensino médio. Se na LDB e nos PCN se atribuía quase que exclusiva responsabilidade pela reorganização curricular aos sistemas de ensino - que por sua vez, exigiam que essa tarefa fosse levada a cabo pelas escolas, i.é, pelos professores -, hoje a realidade é um pouco diferente. Os órgãos fomentadores e reguladores da educação básica brasileira também têm assumido a responsabilidade de criar oportunidades para que os professores efetivem tais mudanças. São provas da maior atenção ao currículo do ensino médio pelos órgãos reguladores o "Programa institucional de bolsas de iniciação à docência" (PIBID) e o "Pacto pelo ensino médio", por exemplo. 


\section{Trans e interdisciplinaridade}

Conforme reconhecem os próprios autores das Diretrizes Curriculares para o Ensino Médio (2013, p. 43 e 44), existem várias metodologias e estratégias de organização curricular, bem como diversas denominações, sendo propostas que tratam da aprendizagem a partir de problemas, centros de interesses, núcleos ou complexos temáticos, elaboração de projetos, entre outras. O que há em comum entre essas diferentes propostas é que visam romper com a organização do currículo cujo foco central é as disciplinas.

Quando falamos em interdisciplinaridade estamos nos referindo à troca, cooperação entre as disciplinas (MORIN, 2004, p. 115). Para efetivar estratégias de organização curricular interdisciplinar é necessário que os professores do ensino médio dialoguem entre si no sentido de identificar pontos de conexão e troca entre os conteúdos das disciplinas que lecionam. A interdisciplinaridade, dizem os autores das Diretrizes Curriculares para o Ensino Médio (2013, p. 44), é uma "[...] abordagem teórico-metodológica com ênfase no trabalho de integração das diferentes áreas do conhecimento". Já a transdisciplinaridade (ou transversalidade) consiste num mecanismo de organização através do qual é possivel transitar (ou atravessar) entre diferentes disciplinas ou áreas de conhecimento utilizando-se de conceitos, eixos temáticos ou problemas (MORIN, 2004, p. 115).

Os documentos federais sobre o ensino médio não prescrevem uma metodologia a ser usada para efetivar a interdisciplinaridade e a transdisciplinaridade curricular. Ao contrário, eles manifestam-se sobre o assunto ratificando que as estratégias integradoras dos currículos devem ser de responsabilidade de cada sistema de ensino e das escolas, sob a alegação de que é preciso considerar as especificidades regionais, sociais e culturais para organizar o currículo de modo interdisciplinar (BRASIL, 2013, p. 45). Entretanto, como sabemos, não é recomendável esperar que o respectivo sistema de ensino público em que atuamos prescreva estratégias para efetivação de currículos interdisciplinares e transversais. Portanto, legalmente cabe às escolas e principalmente aos professores assumir a responsabilidade de propor metodologias e estratégias de ordenação curricular trans e interdisciplinar. 
Em face às demandas em torno de uma melhor qualificação da formação dos estudantes de ensino médio há alguns anos têm-se sustentado que as organizações trans e interdisciplinar dos currículos no ensino médio podem ser alternativas metodológicas viáveis e eficazes às expectativas depositadas na última etapa da educação básica. Nesse sentido, motivado pela indicação de leitura que o professor Ronai Rocha faz em seu livro Ensino de Filosofia e Currículo (2008, p. 61), iniciei a leitura e análise de algumas das contribuições de Donald Winnicott para compreender o desenvolvimento da aprendizagem adolescente e, por conseguinte, entender como que propostas de ensino que conectam as áreas de conhecimento podem contribuir para a formação dos jovens do nível médio.

A ideia mais importante da teoria da formação humana de Winnicott é o conceito de "área intermediária de experimentação" (1975, p. 15). Segundo o autor, a área intermediária de experimentação é a terceira dimensão da natureza humana, cuja existência e importância para o desenvolvimento do ser humano não podemos ignorar e, "para a qual contribuem tanto a realidade interna quanto a vida externa" do sujeito. Winnicott revela ainda a existência de objetos/fenômenos transicionais cuja posse pelos seres humanos, sobretudo na infância, é relevante para o conhecimento da realidade, na medida em que servem de mediadores das dimensões interna e externa do sujeito (WINNICOTT, 1975, p. 28/29), já que permitem a relação do sujeito com as experiências culturais (Arte, Religião e Filosofia, por exemplo). Tais fenômenos transicionais podem ser observados no uso que o bebê faz do urso de pelúcia, da chupeta, do pano, entre outros objetos, ou até mesmo das palavras. O uso dos objetos transicionais possui um caráter lúdico para as crianças e para os jovens em formação. Os fenômenos transicionais são relevantes para o jovem, pois ampliam a experiência cultural do ser humano em formação, na medida em que servem para intermediar a relação entre sua realidade subjetiva e a realidade objetiva. Por "cultura" Winnicott entende como sendo "[...] algo que pertence ao fundo comum da humanidade, para o qual indivíduos e grupos podem contribuir, e do qual todos nós podemos fruir, se tivermos um lugar para guardar o que encontramos" (1975, p. 138).

Segundo o professor Ronai Rocha (2008, p. 65), essas ideias de Winnicott, sobretudo sua noção de área intermediária de experimentação, 
[...] podem nos servir como instrumento conceitual para compreender melhor algumas afirmações para as quais nem sempre temos uma boa elucidação. Eu me refiro aqui aos lugares-comuns que dizem que 'religião não se discute', que 'arte é uma questão de gosto' e que 'Filosofia cada um tem a sua'; esses temas são frequentemente trazidos pelos adolescentes para a sala de aula; mais do que isso, muitos adolescentes trazem para a sala de aula suas 'pequenas loucuras' (a expressão é de Winnicott, em Natureza humana), suas pequenas filosofias e especulações, seus pequenos sistemas de ideias; se o professor apenas acha graça nisso, perde a freguesia antes de abrir o negócio.

Além do conceito winnicottiano de "área intermediária de experimentação" (ou "área transicional") como elemento decisivo para compreendermos o desenvolvimento da formação de crianças e adolescentes, creio que o conceito de "ambiente saudável" de Winnicott também possa contribuir para o melhor entendimento da "experiência cultural" dos jovens. Segundo o autor, o adolescente é um sujeito naturalmente imaturo, sendo que sua imaturidade deve ser preservada, já que é a manifestação de sua saúde. Dado que a imaturidade adolescente representa sua saúde, então todo o acontecimento que interromper o processo natural de amadurecimento será prejudicial ao jovem, tornando-o um falso adulto (WINNICOTT, 1975, p. 198). Ademais, Winnicott afirma que a imaturidade do adolescente representa uma oportunidade da sociedade de realizar experiências e propostas criativas benéficas para ela própria, pois na imaturidade do adolescente "[...] estão contidos os aspectos mais excitantes do pensamento criador, sentimentos novos e diferentes, ideias de um novo viver. A sociedade precisa ser abalada pelas aspirações daqueles que não são responsáveis" (ibid.).

Segundo o professor Rocha, cabe especialmente ao professor de Filosofia assumir o papel de articulador dos conhecimentos a fim de desenvolver 0 pensamento criativo dos estudantes adolescentes, tão abundante nessa fase da vida. Afinal, como mencionado acima, Winnicott considera a Filosofia - juntamente com a Religião e a Arte - umas das experiências culturais por excelência. É importante dizer que, muito embora a especificidade da Filosofia - devido aos assuntos que aborda e aos conteúdos que a compõem - permita, por excelência, ser o ambiente mais propício para a articulação conceitual entre as diferentes 
áreas do conhecimento, a mesma proposta pode ser assumida pelas demais áreas de conhecimento.

Winnicott deixa bastante claro que para atingir a adequada formação do adolescente faz-se necessário um ambiente (familiar ou escolar) em que ele confie, que seja seguro, onde, além disso, suas necessidades sejam reconhecidas (WINNICOTT apud OLIVEIRA e FULGENCIO, p. 70). É preciso deixar claro que ao falar da importância de um ambiente (familiar ou escolar) seguro, confiável e acolhedor para a formação do estudante, o autor está preocupado com outro tipo de segurança e confiabilidade que não apenas a física. Sua preocupação maior diz respeito aos processos psíquicos da formação do adolescente, para os quais os fenômenos transicionais são decisivos. Nesse sentido, parece-me evidente que um ambiente escolar saudável que transmita confiança e acolhimento ao estudante passa também pela organização inter/transdisciplinar do currículo. O professor Ronai Rocha argumenta que cabe à Filosofia a responsabilidade de organizar a articulação curricular - afinal, ela representa "um lugar" onde guardamos nossas experiências culturais mais importantes. Porém, mesmo que essa tarefa de organização curricular seja desempenhada pelo professor de Filosofia, não se segue que apenas essa disciplina esteja envolvida com o processo de reorganização curricular. Ao contrário, o professor Ronai propõe que a reorganização seja levada a cabo por todas as áreas de conhecimento, mas que caberá ao professor de Filosofia, por assim dizer, levar a cabo uma metodologia de união dos conteúdos.

Sendo assim, seguindo a proposta metodológica da transversalidade pedestre procuro planejar aulas interdisciplinares no Colégio de Aplicação identificando conceitos que perpassem outras disciplinas e que mereçam ser elucidados para melhor compreensão dos alunos. Por isso, segue-se abaixo o relato de duas atividades realizadas no CAp/UFRGS nas quais conceitos transversais pedestres foram fundamentais.

\section{Aulas interdisciplinares no CAp/UFRGS}

Apresentarei a seguir três exemplos de aulas interdisciplinares realizadas no CAP/UFRGS. A primeira foi pensada a partir do componente curricular de Filosofia 
"Relativismo moral" e foi lecionada para turmas de segundo ano do Ensino Médio. A segunda aula foi realizada em uma disciplina eletiva denominada "A ciência em Macondo: leituras interdisciplinares", vinculada ao subprojeto PIBID Interdisciplinar Campus do Vale, do qual sou supervisor e a Profa. Gisele Secco é a coordenadora. A terceira foi uma aula relacionando Química e Filosofia, mais especificamente sobre semiótica e representação conceitual.

1) Título da aula: Relativismo moral cultural.

Áreas de conhecimento envolvidas: Filosofia e Línguas Estrangeiras (Alemão, Inglês, Espanhol e Francês). Conceitos transversais pedestres: juízo, cultura e verdade. Descrição das atividades realizadas: o conteúdo que estávamos trabalhando com as turmas de segundo ano sobre o seguinte problema filosófico: os juízos morais possuem valor de verdade objetivo? Diante dessa temática, decidi contatar os professores de língua estrangeira e solicitar-lhes que encontrassem textos sobre a eutanásia é a moralidade dessa ação. Os colegas encontraram matérias em jornais alemães, franceses, espanhóis e norte-americanos sobre o assunto proposto e, como já se esperava, a resposta ao problema não era igual em todos os países.

Posto isso, todos os professores - tanto de línguas estrangeiras quanto o professor de filosofia - entraram juntos em sala de aula para dar início à atividade. Dividimos os alunos de acordo com as línguas estrangeiras que estudam e thes foram distribuídos os respectivos textos sobre o problema da eutanásia, juntamente com 3 questões ${ }^{6}$ que deveriam ser respondidas após a leitura.

Posteriormente à leitura dos textos os grupos apresentaram as respostas para - grande grupo e, dessa forma, toda a turma pôde compreender como os diferentes países em questão respondem ao problema moral da eutanásia, bem como as diferentes justificativas dos países para permitir ou proibir a eutanásia em seus territórios.

Nas atividades descritas até aqui os alunos precisaram pôr em prática suas competências de leitura e interpretação de texto em língua estrangeira. Na etapa

\footnotetext{
${ }^{6}$ As questões eram as seguintes: 1) Qual é o assunto do texto? 2) O texto trata do assunto em qual país? 3) Qual é a resposta do país sobre o problema?
} 
seguinte seus conhecimentos em Filosofia foram mais exigidos porque, mediante os dados obtidos mediante a leitura e interpretação dos textos lhes foi apresentado um argumento sobre a moralidade, ou não, de se realizar a eutanásia. O argumento consistiu no seguinte: (P.1) os países possuem diferentes interpretações sobre a moralidade da eutanásia; (C) portanto, não há uma verdade sobre a moralidade no ato da eutanásia. Esse argumento foi comparado com um argumento do relativismo moral que pode ser expresso assim: (P.1) as pessoas possuem diferentes concepções sobre o que é certo e o que é errado; (C) portanto, não há uma verdade moral sobre o certo e o errado. Frente aos dois argumentos, foi possível demonstrar que ambos se tratam de argumentos inválidos, pois do fato de termos diferentes opiniões sobre $X$, não se segue que não existe uma verdade sobre X. Ou seja, através desse exercício introdutório envolvendo Línguas Estrangeiras e Filosofia os alunos compreenderam a fragilidade de um dos argumentos do relativismo moral cultural sendo que, para tanto, os conceitos transversais pedestres utilizados (juízo, cultura, verdade) serviram de facilitadores da compreensão.

Pôde-se verificar mediante avaliações de Filosofia e de línguas estrangeiras que através da aula interdisciplinar descrita acima os alunos tiveram maior facilidade para compreender o conteúdo filosófico diretamente abordado (Relativismo moral cultural), assim como retomar outros conhecimentos filosóficos fundamentais. No tocante à relação com as culturas dos países de língua estrangeira que participaram da atividade, pôde-se notar que os alunos desenvolveram a habilidade de reconhecer práticas culturais, sociais e políticas diferentes, assim como posicionar-se frente a elas.

2) Uma das atividades interdisciplinares realizadas na disciplina eletiva "A ciência em Macondo: leituras interdisciplinares" foi desencadeada pelo seguinte fragmento do livro de García Marquez:

Em março os ciganos voltaram. Desta vez traziam um óculo de alcance e uma lupa do tamanho de um tambor, que exibiram como a última descoberta dos judeus de Amsterdam. Sentaram uma cigana no extremo da aldeia e instalaram o óculo de alcance na entrada da tenda. Mediante o pagamento de cinco reais, o povo se aproximava do óculo e via a cigana ao alcance da mão. 'A ciência 
eliminou as distâncias', apregoava Melquíades. 'Dentro em pouco o homem poderá ver o que acontece em qualquer lugar da Terra sem sair de sua casa'. Num meio de tarde ardente, fizeram uma assombrosa demonstração com a lupa gigantesca: puseram um montão de capim seco na metade da rua e atearam fogo nele pela concentração dos raios solares. José Arcádio Buendía, que ainda não se consolara de todo do fracasso de seus ímãs concedeu a idéia de utilizar aquele invento como uma arma de guerra (GARCÍA MÁRQUEZ, Gabriel, 2006. P. 9)

Após a leitura conjunta de alguns parágrafos do primeiro capítulo de Cem anos de solidão propusemos aos alunos da disciplina a seguinte pergunta: é possível fazer uma guerra usando a luz solar e lentes de vidro como armas, conforme pretendeu José Arcádio Buendía? Na aula seguinte, organizamos uma aula sobre lentes e luzes com o intuito de responder a pergunta proposta na aula anterior. A aula foi guiada pelos bolsistas do curso de licenciatura em Física que explicaram o funcionamento da luz, os diferentes tipos de lentes, os efeitos das luzes nas diferentes lentes e a relação do ponto de concentração da luz com a intensidade do calor por elas produzido, o funcionamento dos telescópios e microscópios. $\mathrm{Na}$ sequência foi exibido o vídeo de uma experiência com lentes de aumento (lupas) usadas para provocar fogo em fósforos e papéis. Na mesma aula os alunos foram convidados a ir ao pátio do Colégio e lá lhes foram distribuídas várias lupas e fósforos e suas tarefas é produzir fogo com esses utensílios. Usando dos conhecimentos adquiridos em sala de aula minutos antes, os alunos conseguiram repetir a experiência exibida no vídeo e conseguiram provocar fogo nos fósforos usando as lentes. Por fim, foi perguntado aos alunos se a intenção de José Arcádio Buendía seria exitosa, i. é, se seria possível usar a luz solar e lentes de aumento como arma em uma guerra. A resposta dos alunos foi de que seria possível desde que existissem lentes grandes o suficiente para captar a luz solar e concentrá-las em um único ponto.

Portanto, a aula oportunizou o diálogo entre diferentes disciplinas tradicionalmente presentes nos currículos de nível médio e teve como elemento desencadeador o espírito investigativo, desafiador e inquietante de José Arcádio Buendía, personagem de Gabriel García Márquez. 
3) Título da aula: "Por que os componentes químicos são representados assim?"; áreas de conhecimento envolvidas: Química e Filosofia; conceitos transversais pedestres: representação e conceitos; descrição da aula: em uma aula de Química no segundo ano do Ensino Médio os alunos questionaram a professora da disciplina sobre por que os componentes químicos eram representados por aquelas letras e naquelas ordens. Mais especialmente, alguns alunos da turma queriam saber por que o Cloreto de Sódio é representado por "NaCl" e não, por exemplo, por XYZ. Diante dessa pergunta, professora da disciplina respondeu a turma que não obtinha uma boa resposta no momento, mas que iria tentar saná-la no próximo encontro. Foi nesse momento que a professora de Química entrou em contato comigo e propôs que realizássemos uma aula interdisciplinar. Aceitei a proposta e decidimos que na aula seguinte faríamos uma aula de Filosofia e Química a partir do conceito de representação. Iniciamos a aula retomando as inquietações dos alunos e introduzindo o esclarecimento do conceito de representação e o problema de filosofia da linguagem sobre a relação entre as palavras e as coisas que elas representam. No momento seguinte introduzi os conceitos de semiótica de C. Peirce: ícone, índice e símbolo. Dessa maneira, foi possível demonstrar à turma que os componentes químicos são representados por letras e números, em virtude de diferentes motivos: por haver uma relação de causalidade entre a representação do objeto e o próprio objeto; por haver uma representação de semelhança entre ambos ou por ser uma representação arbitrária. Os alunos receberam muito bem a proposta e demonstraram ter sanado suas dúvidas iniciais. Dessa maneira, a aula demonstrou-se relevante não apenas por ter introduzido esclarecimentos conceituais de Filosofia da Linguagem como também auxiliou a turma a melhor compreender noções fundamentais de Química e Filosofia da Ciência.

\section{Considerações finais}

Conforme busquei demonstrar, estamos caminhando rumo à efetivação de significativas mudanças na estrutura curricular da educação pública brasileira. Gradativamente as exigências e prescrições dos documentos nacionais de educação têm enfatizado a necessidade dos professores repensarem suas práticas 
pedagógicas com vistas a estabelecer maiores conexões entre diferentes disciplinas para que, dessa forma, as aulas façam mais sentido para os jovens alunos. Entendo que uma das maiores vantagens do atual contexto educacional brasileiro no tocante às discussões curriculares, em comparação às décadas anteriores, repousa no reconhecimento por certas instâncias reguladoras e administrativas de que para qualificarmos a educação básica é preciso, entre outras ações, mudar também a concepção curricular dos cursos de licenciatura. Creio que projetos como o PIBID, por exemplo, representam valiosas iniciativas que lançam luz ao futuro da educação básica pública brasileira.

Em relação ao método, tenho defendido que a proposta da transversalidade pedestre é uma excelente oportunidade motivadora de diálogos entre as disciplinas, conforme tenho observado através de algumas ações interdisciplinares planejadas e executadas no Colégio de Aplicação da Universidade Federal do Rio Grande do Sul (CAp/UFRGS). Contudo, deve-se reconhecer que a identificação de um bom método de articulação curricular no ensino médio não é condição suficiente para atingir as demandas em relação à última etapa da educação básica, pois além da disposição para dialogar com os colegas das demais áreas, é preciso muito estudo para além de nossa própria área de formação.

Com todo o esforço para articular os componentes curriculares foi possível notar o aumento do interesse dos alunos pelas aulas de Filosofia e das disciplinas envolvidas - conforme relato dos professores; aplicação dos conhecimentos adquiridos pelos alunos nas aulas descritas em atividades de outras disciplinas, conforme relato dos mesmos, e maior iniciativa dos alunos no sentido de identificar pontos de conexão entre os conteúdos das aulas de Filosofia com os das demais áreas. Portanto, entendo que a utilização da metodologia da transversalidade pedestre contribui significativamente para o desenvolvimento das competências e habilidades que os documentos e normativas sobre educação básica asseveram que o ensino médio deve promover nos jovens estudantes. 


\section{Referencias bibliográficas:}

BRASIL. Lei de diretrizes e bases da educação nacional: lei 9.394 , de 20 de dezembro de 1996. Brasília: DF, 1996.

- PCN+ Ensino Médio: orientações educacionais complementares aos Parâmetros Curriculares Nacionais. Brasília, 2002.

GARCÍA MÁRQUEZ, Gabriel. Cem anos de solidão. Tradução de Eliane Zagury; ilustrações de Carybé. RJ: Record, 2006.

Diretrizes Curriculares Nacionais para a Educação Básica. Brasília, 2013.

MORIN, Edgar. Os setes saberes necessários à educação do futuro. Trad. de Catarina Eleonora F. da Silva e Jeanne Sawaya. São Paulo: Cortez. Brasília, DF: UNESCO, 2000.

OLIVEIRA, Daniela Machado de; FULGENCIO, Leopoldo Pereira. "Contribuições para o estudo da adolescência sob a ótica de Winnicott para educação". In: Psicologia em revista. Belo Horizonte, v. 16, p. 64 - 80. 2010.

ROCHA, Ronai Pires da. Ensino de Filosofia e Currículo. Petrópolis, RJ: Vozes, 2008.

WINNICOTT, D. W. O brincar e a realidade. Tradução de Jayme Salomão. Rio de Janeiro: Imago editora. 1975. 